\title{
Presentación \\ Una panorámica del sector bancario después de la crisis
}

\author{
Emili Tortosa-Ausina \\ Universitat Jaume I e Ivie
}

Durante la última década, el sector financiero internacional y la industria bancaria se han visto sometidos a fuertes vaivenes de diversa índole. Lo que ha sido en gran medida un tortuoso camino vino marcado por el inicio de la crisis financiera, con un punto de partida común en muchos países, tanto por el momento en que se inició como por sus causas. Causas relacionadas con una excesiva asunción de riesgos, en general, y una elevada exposición al sector inmobiliario, en particular. El alto grado de integración de los sistemas financieros internacionales propiciaron el resto, contribuyendo a una rápida propagación de la crisis (que afectó en menor medida a países menos integrados desde un punto de vista financiero).

Si bien muchos otros factores han jugado un papel esencial, las distintas autoridades económicas y monetarias no respondieron ni de igual forma ni de manera sincronizada ante las amenazas, reales y potenciales, que afectaban a la industria bancaria y, en última instancia, a la economía real. Por tanto, la salida de la crisis que contagió de manera generalizada a gran parte de las economías más avanzadas ha sido y está de hecho siendo desigual pero, en el caso concreto de la Unión Europea, las medidas tomadas por el Banco Central Europeo en los últimos años han facilitado que el desarrollo financiero pueda volver a preceder positivamente al desarrollo económico.

Las lecciones que se han aprendido durante esta década han sido muchas y, por tanto, el panorama actual del sector bancario en Europa y, sobre todo, en España, es muy diferente, hasta el punto de que se habla de un new normal o «nuevo normal» para la banca, si bien todavía estamos en un proceso de transición hacia el mismo. Asimismo, la tendencia observada hacia la desregulación del sector en los años previos a la crisis se ha revertido totalmente y, en los últimos años, son muchas las iniciativas destinadas a re-regular el sector, y que están configurando un panorama muy distinto al existente hace una década.

En el caso concreto del sector bancario español, en proceso de recuperación (no sin algunas sombras tales como la reciente crisis del Banco Popular), el panorama actual es muy diferente al existente con anterioridad a la crisis. Un reflejo del mismo vendría dado por las opciones que tiene un cliente potencial cuando se plantea operar con una entidad bancaria, pues de los tres grandes agregados institucionales que existían con anterioridad a la crisis, esto es, bancos, cajas y cooperativas, las segundas han dejado de ser tales prácticamente en su totalidad para acabar convirtiéndose en bancos comerciales. 
Junto a este panorama que se ha creado tras la crisis, el futuro inmediato presenta muchos retos al sector, algunos de los cuales serán objeto de análisis de los trabajos presentados en este número monográfico, y multitud de incógnitas de las que, por el momento, no tenemos respuestas claras, tanto a nivel de España como de la Unión Europea, y tanto de índole más general como de tipo más específico. Algunas de estas incógnitas estarían relacionadas, por ejemplo, con el tamaño óptimo de la red de oficinas en España (que ha pasado de las alrededor de 45.000 en 2008 a poco más de 28.000 en la actualidad y cuántas se cerrarán en los próximos años), qué debería hacer el sector bancario para mejorar su imagen, qué responsabilidad tiene el Banco Central Europeo en la baja rentabilidad del sector bancario, cuál será el papel de las fintech y el verdadero impacto de la banca digital, cuáles serían las amenazas de la unión bancaria para la viabilidad de las entidades de pequeño tamaño, si podría haber riesgo de que se resienta la competencia en el sector como consecuencia del aumento de la concentración, cuándo empezará a aumentar el stock vivo de crédito en España, o qué medidas podrían adoptarse para dar salida al elevado volumen de activos adjudicados que hay en los balances de la banca española.

Algunas de estas cuestiones y también otras distintas serán objeto de estudio en los trabajos que integran el número monográfico. Las diferencias al comparar los sectores bancarios antes y después de la crisis son de tal calado que resulta cuanto menos complejo analizar todos los cambios que ha habido y las preguntas que se han podido suscitar mediante unas pocas contribuciones. Entendemos, no obstante, que los estudios recopilados en este número no solo mejoran el entendimiento de lo ocurrido en los últimos años en la industria bancaria española y europea, sino también contribuyen a dar respuestas a algunos de los retos que se plantean.

En el primero de los artículos, Ana Lozano-Vivas y Flores Martínez Alba se ocupan de analizar las relaciones entre ciclo financiero y estabilidad bancaria, centrando su estudio en el caso particular del sector bancario español. A partir de una muestra de más de 20 años (1995-2016), en el trabajo se evalúa hasta qué punto la estabilidad del sistema bancario atenúa o exacerba el ciclo financiero. Sus resultados ponen de relieve que el ciclo financiero en España se define con precisión a través del crédito como porcentaje del PIB, el crédito al sector privado no financiero, y los precios de la vivienda. Por otra parte, la brecha entre crédito y PIB constituye un buen indicador anticipado de la crisis bancaria en España. Por último, una desviación exógena de la relación entre la provisión por insolvencias de su valor potencial conduce a una suavización del ciclo. Por tanto, la regulación relativa a las provisiones dinámicas españolas podría constituir un buen instrumento para su uso como herramienta macroprudencial para evaluar la prociclicidad del sistema financiero.

Por su parte, Cristina Ruza y Marta de la Cuesta analizan el negocio bancario yendo más allá del enfoque tradicional de gestión de riesgos financieros, poniendo un mayor énfasis en el conjunto de riesgos que afectan a su imagen corporativa. Los consumidores como usuarios últimos de los productos y servicios bancarios han cobrado un especial protagonismo en los últimos tiempos y están ejerciendo un papel muy activo en defensa de sus intereses. En el artículo se examinan datos sobre 
el mecanismo de supervisión de entidades bancarias en España estructurado en dos niveles y se analiza el contexto y los principales retos a los que tienen que enfrentarse las entidades financieras en nuestro país.

En el caso del trabajo de Juan Fernández de Guevara y Carlos Salvador, los autores se ocupan del impacto que la política monetaria expansiva mantenida por los bancos centrales a raíz de la crisis financiera en los ratings de los bancos de la Unión Europea, los Estados Unidos y Japón durante los años 2004-2013. El papel de las agencias de calificación fue clave durante (y, especialmente, con anterioridad a) la crisis, pero su evaluación no ha sido objeto de toda la atención que merecería. Como hemos apuntado en párrafos precedentes, los reducidos tipos de interés y las escasas diferencias entre los tipos a corto y a largo plazo suponen una amenaza de futuro para el sector bancario. Los resultados obtenidos muestran que el efecto tanto de los tipos de interés así como la curva de tipos sobre los ratings bancarios tiene forma de U invertida en las tres grandes agencias de calificación Fitch, Moody's y Standard and Poor's, de forma que incrementos de los tipos de interés y/o variaciones de la pendiente de la curva de tipos tendría efectos beneficiosos sobre los ratings cuando estos son bajos, pero ulteriores subidas tendrían un efecto menor, agotándose su impacto e incluso pudiendo llegar a ser negativo. Los autores realizan también una serie de simulaciones, las cuales indican que el efecto máximo de los tipos de interés se obtiene en niveles del entorno del 2,5 por 100 en Standard and Poor's y del 4,5 en Moody's y Fitch.

El examen de la posición del sector bancario español en el contexto europeo y los cambios que han tenido lugar tras la reestructuración llevada a cabo para corregir los desequilibrios acumulados en la anterior etapa de expansión es el objetivo principal del que se ocupan Paula Cruz y Joaquín Maudos. Para ello, analizan la evolución de 2008 a 2016 en variables tales como la estructura de mercado, modelo de negocio, márgenes, rentabilidad, eficiencia, solvencia, etc. Sus resultados indican que la reestructuración, saneamiento y capitalización han dado sus frutos corrigiendo los problemas del pasado. Sin embargo, la rentabilidad actual es reducida e insuficiente para atraer al inversor, debido a factores tales como las exigencias regulatorias, el elevado volumen de activos improductivos y el entorno de tipos de interés muy reducidos. Esto exigiría no solo más respuestas sino que, además, estas deberían ser de nuevo calado, apuntando en tres direcciones: ajustes en la capacidad instalada, diversificación de la estructura de ingresos y digitalización de la actividad bancaria.

Judit Montoriol se ocupa de uno de los principales desequilibrios macroeconómicos que afectan a la economía española, esto es, su elevado endeudamiento, tanto público como privado. A pesar de que desde 2012 el endeudamiento total de la economía ha empezado a descender, el volumen total es todavía muy elevado, y la dependencia de la financiación externa apenas se ha reducido. En su estudio, la autora examina la evolución del endeudamiento de la economía española entre 2000 y 2016 por sectores, prestando particular atención al papel primordial del sector bancario y su dependencia de la financiación externa. Entre las conclusiones del trabajo podemos destacar que la reducción de la deuda externa (pública y privada) 
hacia niveles sostenibles es un factor clave de cara a mejorar la capacidad de crecimiento y así reducir la vulnerabilidad externa de la economía española.

Los efectos de la reciente crisis financiera en la competencia bancaria y la oferta de crédito en Europa son objeto de análisis en el trabajo de Nuria Suárez y Elena Cubillas. Las autoras aplican un procedimiento en dos etapas a una muestra de 610 entidades, proporcionando evidencia de cómo el impacto negativo de la crisis en la oferta de crédito se ha visto contrarrestado por el incremento en el poder de mercado bancario medio experimentado desde 2008. Sus resultados llevan a concluir que el efecto se observa especialmente en entornos con menor calidad institucional, más exigentes en el cumplimiento del capital regulatorio, y allí donde no existen elevadas restricciones a las actividades bancarias no tradicionales.

El trabajo de Juan Segurado se ocupa de un aspecto relacionado con el nuevo marco regulatorio, más exigente, que afecta a la banca española y europea en la actualidad. En concreto, el objetivo de la revisión fundamental del conocido como trading book fue superar las deficiencias conceptuales del anterior marco de riesgo de mercado. La nueva definición de límites proporciona criterios más objetivos para colocar instrumentos en la cartera de negociación, aunque su impacto real depende de la implementación de supervisión. El nuevo enfoque estandarizado es un marco más sensible al riesgo y más capaz de actuar como un repliegue a los modelos internos, pero aún quedan algunos desafíos. El nuevo enfoque de modelos internos mejora la captura de riesgos de liquidez, incorporando varias características para reducir la variabilidad del peso de riesgo, si bien la evidencia sobre este último solo se obtendrá tras su implementación.

Los últimos dos trabajos del monográfico tratan de aspectos relacionados con la localización geográfica de oficinas bancarias en España. En primer lugar, Lucio Fuentelsaz, Minerva González y Sergio Palomas profundizan en los principales factores que explican la fuerte caída en el número de oficinas bancarias que ha tenido lugar en España en los últimos años desde un enfoque eminentemente descriptivo. Tras una visión panorámica del sector y de sus principales entidades, confirmando la notable reducción en la red de oficinas en la mayoría de ellas, el trabajo discute las que pueden ser las principales causas de este patrón mediante comparaciones estadísticas del comportamiento seguido por cada entidad en función de estos factores y de un análisis de descomposición de la varianza, para evaluar la importancia relativa de cada uno de estos factores. Los resultados indicarían que la caída en el volumen de negocio es el principal detonante de esta reducción en la red. Por contra, factores como el desarrollo tecnológico o las diferencias en los niveles de eficiencia parecen haber tenido un peso marginal en dicha explicación.

El último artículo del monográfico se ocupa de una temática similar, si bien desde un punto de vista diferente que lleva a complementar las conclusiones obtenidas en el trabajo previo. En su contribución, David Conesa, Priscila Espinosa, Anabel Forte y Emili Tortosa-Ausina se ocupan de algunas de las implicaciones de la caída en el número de sucursales bancarias. Las implicaciones de esta tendencia son notables, pues el acceso a la oficina física sigue siendo clave en comunidades remotas 
y/o desfavorecidas, además de existir un impacto todavía no medido en términos de banca relacional. A través de un modelo estadístico, los autores evalúan si los fenómenos de over-branching y under-branching, esto es, exceso o escasez de oficinas, han estado presentes en el sector bancario español entre 1999 y 2011. La respuesta indicaría que la existencia de dichos fenómenos depende del tipo de entidad considerada (banco, caja o cooperativa), suponiendo la reestructuración del sector cajas de ahorros una amenaza para el acceso a los servicios bancarios en algunas regiones. 